Editorial

\title{
Introduction: Gender's Influence on Genealogy Narratives
}

\author{
Amy M. Smith \\ Media \& Communication Department, Salem State University, Salem, MA 01970, USA; asmith@salemstate.edu; \\ Tel.: +1-978-542-6937
}

Received: 14 August 2018; Accepted: 14 August 2018; Published: 17 August 2018

check for updates

Images. Deeds. Records. Moments. Memory. History. Herstory. Story.

These tiny words all represent some piece of the family genealogical puzzle. They may mean more to some than others, but for those doing the work they represent a time and a space that opens doors (or sometimes windows) into the past. Goodall (2005) tells us that we inherit our family story from those who came before us. Sometimes that story is complete, we know who we are, where we are from, and how the story impacted our lives. But other times investigating our narrative inheritance (Goodall 2006) is risky business. Those doors might have been locked by those who came before us. They may be bolted shut, penned up with nails and wooden cross bars.

The very nature of official/governmental data closes and locks many of those doors for women and women's stories. The gender inequalities in the genealogy narrative can sometimes overwhelm even the most seasoned of researchers. The other side of that spectrum is a rich collection of women's stories through less formal channels, such as journals and diaries or inherited heirlooms.

In each of the essays contained in this special collection we get a clearer understanding of Gender's Influence on Genealogy Narratives. When sending out the call for this special issue my vision was to compile scholarly research that enriched our understanding of the intersection of gender and genealogy. I wanted to include vibrant narratives that prioritized the personal over the data and worked toward a reclamation of women's history through a genealogical lens. The articles contained here demonstrate how gender not only shapes genealogy and family narratives, but the impact it has upon culture over time.

Knight's (2017) research centers around a case study of female legacy within family history. Using oral history, a well-regarded genealogical tool that often falls to the older generation for record-keeping and story management (Kornhaber 1996), Knight works to show the role of women within the family and the economic success of the family. Using historical documents such as census records, legal documents, wills, deeds, newspaper articles, and church records Knight builds a framework for this family narrative that is engaging and enticing. Knight's research portrays women as strong and influential to the family's history and legacy, highlighting the records of accomplishment and achievement across generations.

Yamaguchi (2017) offers a rich portrait of the oldest mortuary serving the Japanese American community in Los Angeles. This research examines the intersections of gender, death, ethnicity, and nationality after World War II. Yamaguchi highlights the cultural and traditional practices as a method for framing the power and institutional structures at play in the death/burial process. This five-generation family mortuary is the site of community rituals as well as a vital record- and memory-keeper for the Fukui family. Using ethnographic and autoethnographic methods, Yamaguchi situates her own lineage within the Fukui family while contextualizing the importance of the mortuary within the Japanese American culture in Los Angeles.

Peters (2017) research works at the center of gender and racial family narratives in its examination of the lives of free people of color pre-20th century. Peters, a Roberts Settlement descendent, examines 
this mixed-race community in Indiana and applies a lens of Black feminist thought and poetic inquiry to underpin this work. In examining both old and new family/Settlement narratives to better understand the lived experience of being a Black woman in Indiana, this research is able to identify the way the dominant male narratives often marginalize the stories of Black women.

Wagner's (2017) readers are offered a perspective on the impact of genealogical data on identity. Grounded in research on intertextual memory and family matrilineal health narratives, Wagner "challenges humanistic conception of identity as inherent, atomistic, and highly dependent on successful memory performance". This intertextual approach to memory performance can help caregivers and healthcare providers to reimagine Alzheimer's patients in ways that are separate from their medical health and cultural tropes. Wagner nicely addresses the empirical research regarding the failure in Alzheimer's literature to consider ways caregivers interact with patients and their advocates. This research offers ways to improve on that communication for healthier patient, caretaker, and advocate relationships.

Schroer and Hine (2017) use case study results from a service learning project to present a vibrant narrative of the Western frontier in the 1800's. Their research examines genders relation to social identity and master status. Arguing that, in contrast to existing literature regarding gendered epitaphs on gravestones, the epitaphs chosen by surviving family members in the Crooked Creek cemetery demonstrate the significant contributions of women in development of the pioneer village. Due to these findings Schroer and Hine advocate for a reconsideration of the role of wife and/or mother to write more historically situated narratives of family and community histories.

Returning to the World War II era, Owens Patton (2017) focuses on the family narratives often constructed by the union of Black servicemen and white German women. Working with a framework of memory and post-memory, Owens Patton uses autoethnography, family interviews, and family narratives to better understand how these unions were situated in a historical context and the role Black German children and mothers occupied in the German national imagination. Owens Patton interrogates the notion that "individual rights and interests were superseded by the assertion of state interest in managing German citizenry" and argues that "identifying Germanness as "white" comes at the expense of German women's rights over their bodies and the exclusion of mixed race Black German children".

Individually, each of these articles contributes significantly to the field of genealogy research at the intersection of gender. Together, they provide the reader an opportunity to deeply engage with the common themes that tie these articles together. As guest editor, I believe this issue answers the call to prioritize the personal, understand the myriad of ways gender shapes family narratives and genealogy as well as historical culture, and aims to reclaim women's history within the genealogical sphere.

Funding: This research received no external funding.

Conflicts of Interest: The author declares no conflicts of interest.

\section{References}

Goodall, Harold L., Jr. 2005. Narrative inheritance: A nuclear family with toxic secrets. Qualitative Inquiry 11: 492-513. [CrossRef]

Goodall, Harold L., Jr. 2006. A Need to Know: The Clandestine History of a CIA Family. Walnut Creek: Left Coast Press, Inc.

Knight, Thomas Daniel. 2017. Gender as a Determining Factor in the Family History and Development of the McGee Family. Genealogy 1: 17. [CrossRef]

Kornhaber, Arthur. 1996. Contemporary Grandparenting. Thousand Oaks: Sage Publications.

Owens Patton, Tracey. 2017. That was the Worst Day of My Life: Recrafting Family through Memory, Race, and Rejection in Post-WWII Germany. Genealogy 1: 11. [CrossRef]

Peters, Charnell. 2017. The Genealogy of Roberts Settlement Explored through Black Feminist Autoethnography. Genealogy 1: 14. [CrossRef] 
Schroer, Sandra, and Ellen Jayne Hine. 2017. Investigating Gender on the Frontier: 19th-Century Crooked Creek Cemetery. Genealogy 1: 12. [CrossRef]

Wagner, Kirstin. 2017. Amamnesis: Intertextual Memory and Alzheimer's Disease. Genealogy 1: 13. [CrossRef] Yamaguchi, Precious. 2017. Keeping the Culture of Death Alive: One Hundred Years of a Japanese American's Family Mortuary. Genealogy 1: 15. [CrossRef] 